\section{OFICINAS SOBRE EL FRIGORIFICO DE COALSA, EN EL PUERTO DE LA CORUÑA/ESPAÑA}

Elisa López Favre, Arquitecto

Rafael Astor Casalderrey, Ingeniero de Caminos

Colaborador:

Javier Poole Pérez-Pardo, Ingeniero de Caminos 131-144

\section{SINOPSIS}

Este proyecto surgió de la necesidad por parte de COALSA de ampliar las oficinas existentes hasta ahora en el sótano de un edificio del puerto de La Coruña.

La infraestructura de las nuevas oficinas se realizó mediante zapatas de hormigón, con un canto de $50 \mathrm{~cm}$. En el interior de las cámaras frigorificas se reforzaron los pilares por medio de unos perfiles en los que se inyectó mortero sin retracción formando asi una especie de capitel metálico. Con este sistema de capitel y zapata se consiguió asegurar tanto el aislamiento como la capacidad portante.

La comunicación por el exterior se realiza a través de dos cajas de ascensores de chapa de aluminio y una escalera cuyo núcleo es a base de pantalla de hormigón.

El resto de la estructura es metálica galvanizada de color amarillo, excepto los paramentos que son de cartón-yeso-cartón.

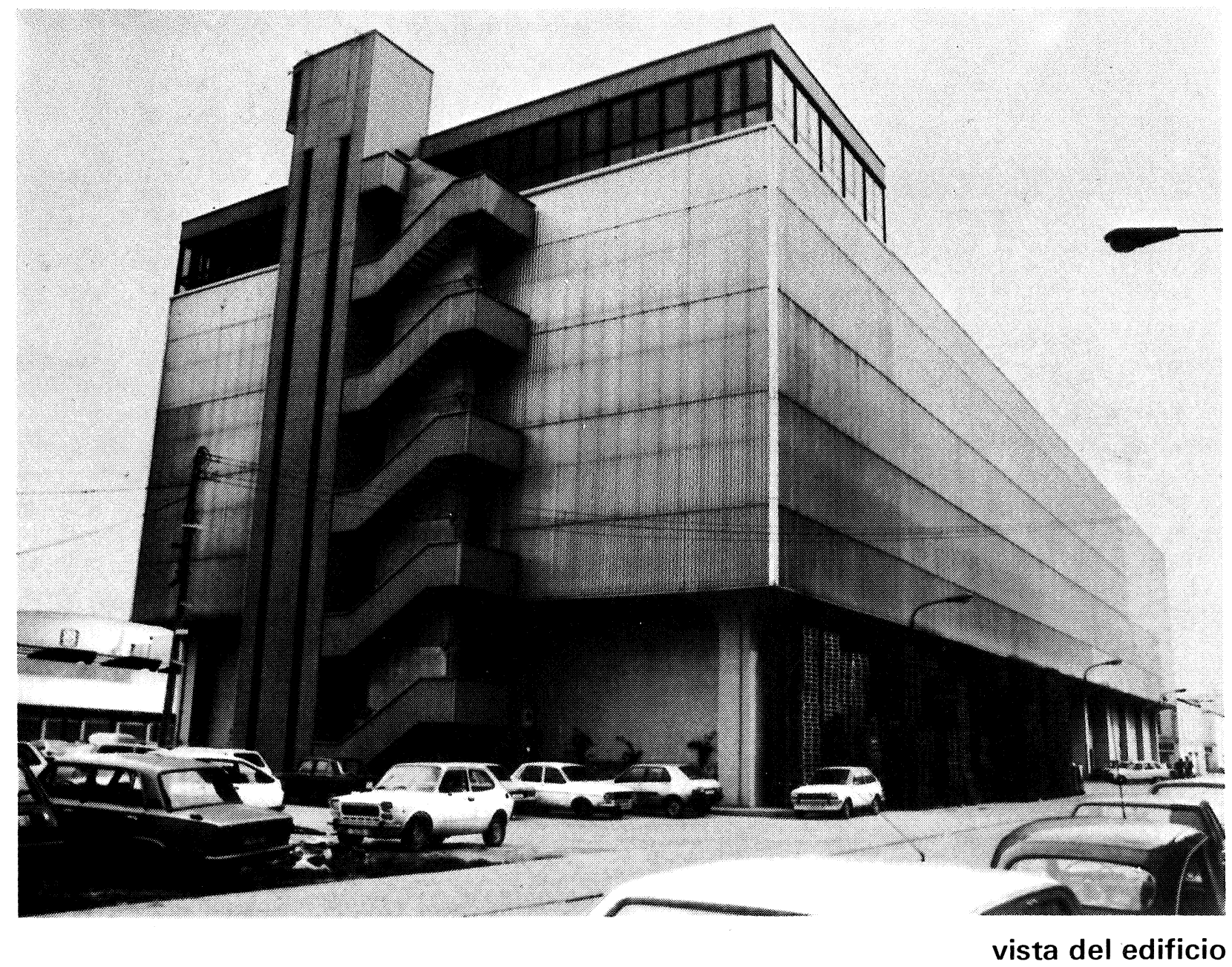


El frigorífico de COALSA (Conservación de Alimentos, S. A.) se encuentra situado en terrenos de la Junta de Obras del Puerto de La Coruña, en el Muelle del Este, con una planta de $2.662 \mathrm{~m} 2$. Construido en el año 1965, el edificio, dedicado a la conservación del pescado y a la fabricación de hielo en escamas, consiste en dos plantas altas dedicadas a cámaras frigoríficas y fábrica de hielo, una planta baja para manipulación de la mercancía y un sótano en el que se encuentran las máquinas y las oficinas.

Exteriormente el edificio consiste en un proporcionado paralelepípedo cuyas caras han sido tratadas a base de chapa de aluminio sin pintar soportado por unos robustos pilares de hormigón - retranqueados respecto a los planos de las caras - que se rematan al alcanzar el paralelepipedo en unos capiteles, los cuales forman parte de un forjado reticular el cual queda visto y forma la parte inferior del paralelepipedo. En la planta baja los paramentos han sido retranqueados para permitir destacar los pilares realizados con obra de fábrica, lo cual separa visualmente el cuerpo superior.

\section{planta de oficinas}

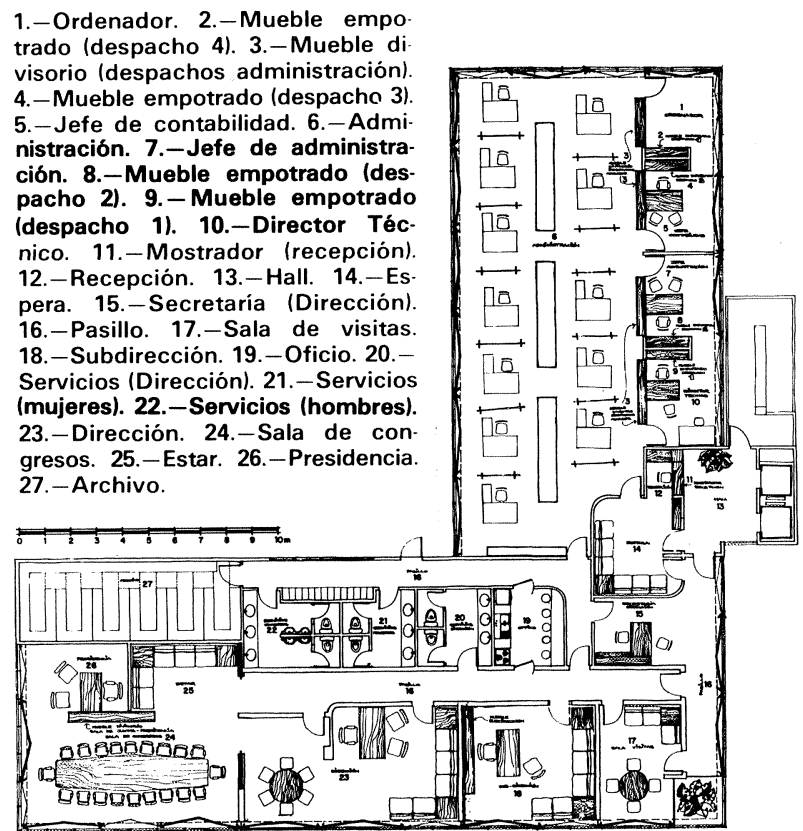

En este proyecto destacan de forma particular dos características: primera, que la ubicación de las oficinas, dada la forma del edificio y que es una concesión del Puerto que ocupa toda la planta de la parcela, ha de realizarse en la cubierta a 21,28 m sobre el nivel del muelle;

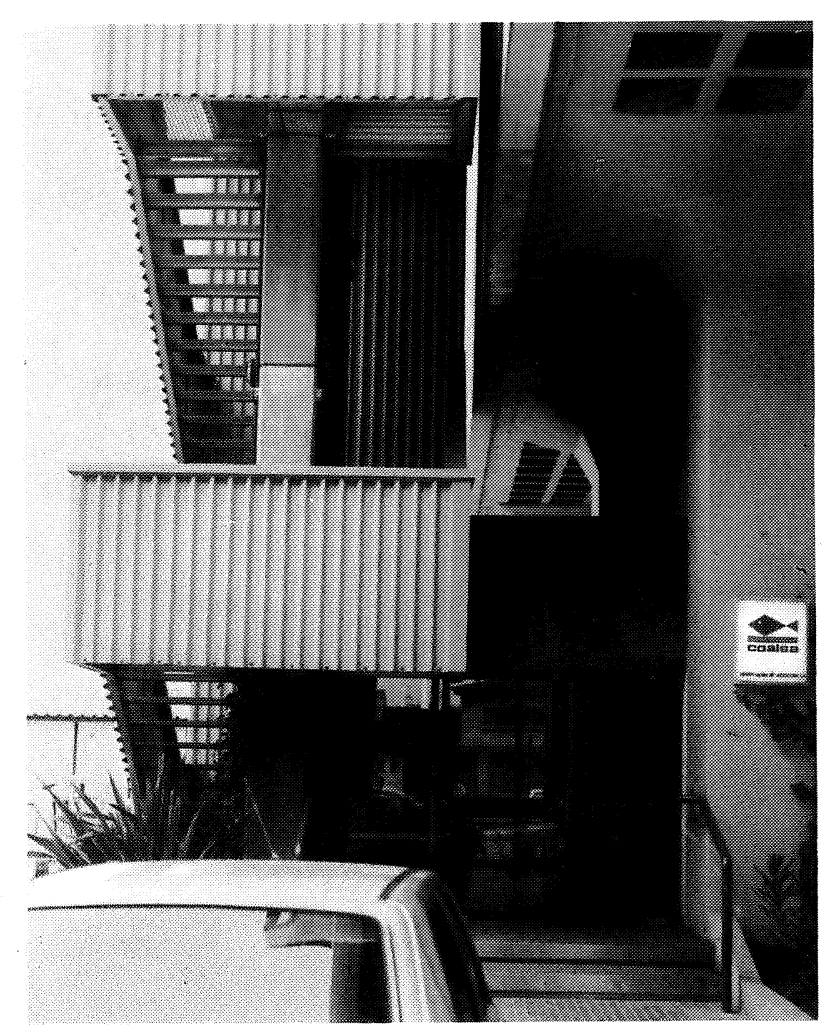

\section{entrada principal}

segunda, que dada la línea bella y funcional del edificio, toda solución ha de contemplar la estética de forma fundamental.

Se presentó la necesidad de disminuir $y$, a ser posible, evitar todo puente térmico entre el interior de las cámaras $\left(\mathrm{a}-32^{\circ}\right)$-las cuales se encuentran bajo la cubierta- y el exterior, asi como el imperativo de resolver el acceso a las oficinas, ya que por el interior no se puede realizar, impidiéndolo la actual distribución.

Desde la primera planta el edificio cambia de estructura $y$, en esencia, se compone de unos pilares de hormigón que soportan vigas metálicas, las cuales vuelan lo necesario para, a base de correas metálicas, dar sustentación al aislamiento (foamglas) y a la chapa metálica de cerramiento. En la cubierta las vigas metálicas se completan con correas, sobre las cuales se ha tendido el mismo aislamiento que en las paredes y sobre él una capa de hormigón de protección de unos $3 \mathrm{~cm}$ de espesor. Sobre esta capa, con tabiquillos y planchas de fibrocemento, se forman las dos aguas que vierten a un canalón central. Todo está rematado perimetralmente con un peto uniforme que es el responsable de la definitiva forma de paralelepipedo del edificio. 


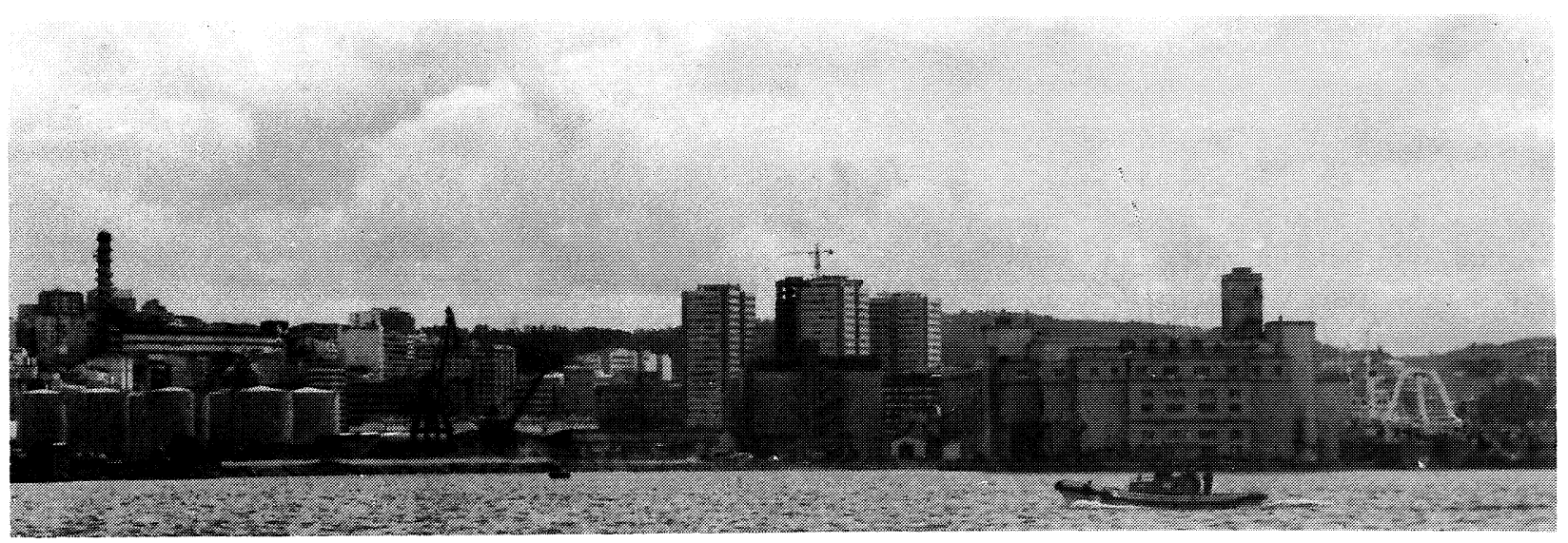

La infraestructura de la oficina consiste en una cimentación a base de zapatas de hormigón (la única obra húmeda, junto con el núcleo de la escalera) a realizar en la cubierta del frigorifico (a cota 21,80 ) y sobre la capa de hormigón que se encuentra bajo el fibrocemento. Estas zapatas con un canto de $50 \mathrm{~cm}$ reciben la red de las vigas metálicas que soportan el suelo de la oficina y los pilares metálicos que soportan la cubierta y el cerramiento. La disposición de las zapatas se realiza según la cuadricula de pilares del frigorífico, de tal forma que al estar éstos retranqueados respecto al paramento, tienen que surgir de las zapatas perimetrales los vuelos necesarios para restituir las caras planas del edificio. En el interior de las cámaras, y debajo del aislamiento, se refuerzan los pilares

\section{vista general}

y la transición de éstos al sistema de vigascorreas, formándose una especie de capitel metálico (con las dimensiones de las zapatas en planta) a base de unos perfiles entre los que se inyectó mortero sin retracción.

Las dimensiones de las zapatas $y$, por tanto, de los capiteles son consecuencia tanto de la función de aislamiento como de la función de resistencia a las cargas que esta estructura tiene que cumplir. La tensión admisible se determinó por ensayos de muestras en los laboratorios de Eptisa, en La Coruña.

El acceso a las oficinas, y puesto que no se podia realizar por el interior del edificio (excepto una posible salida de emergencia) hubo que

frigorífico

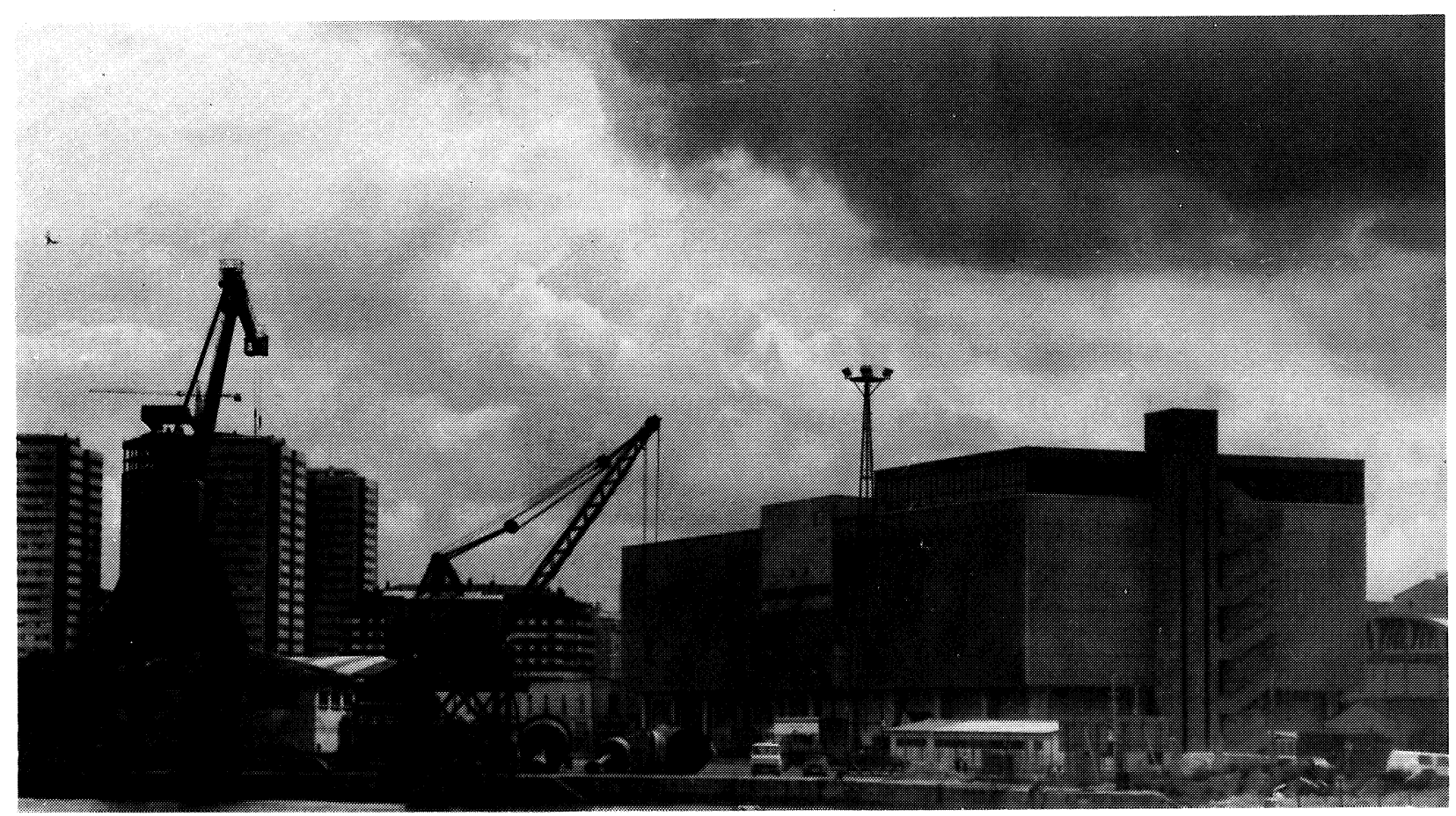


planteárselo por el exterior y debido a que al ser en terrenos del Puerto (para lo cual se requiere nueva concesión), se propuso fuera el menor posible. La comunicación vertical (2 ascensores y escaleras) se proyectó de acuerdo con el tratamiento del edificio a base de chapa de aluminio para las cajas de ascensores, excepto dos ventanales a lo largo de la caja -que permite observar en la ascensión el bello espectáculo del puerto y bahía coruñesa- y el núcleo de la escalera a base de una pantalla de hormigón alrededor del cual se desarrolla la escalera. Esta escalera dado el poco uso que

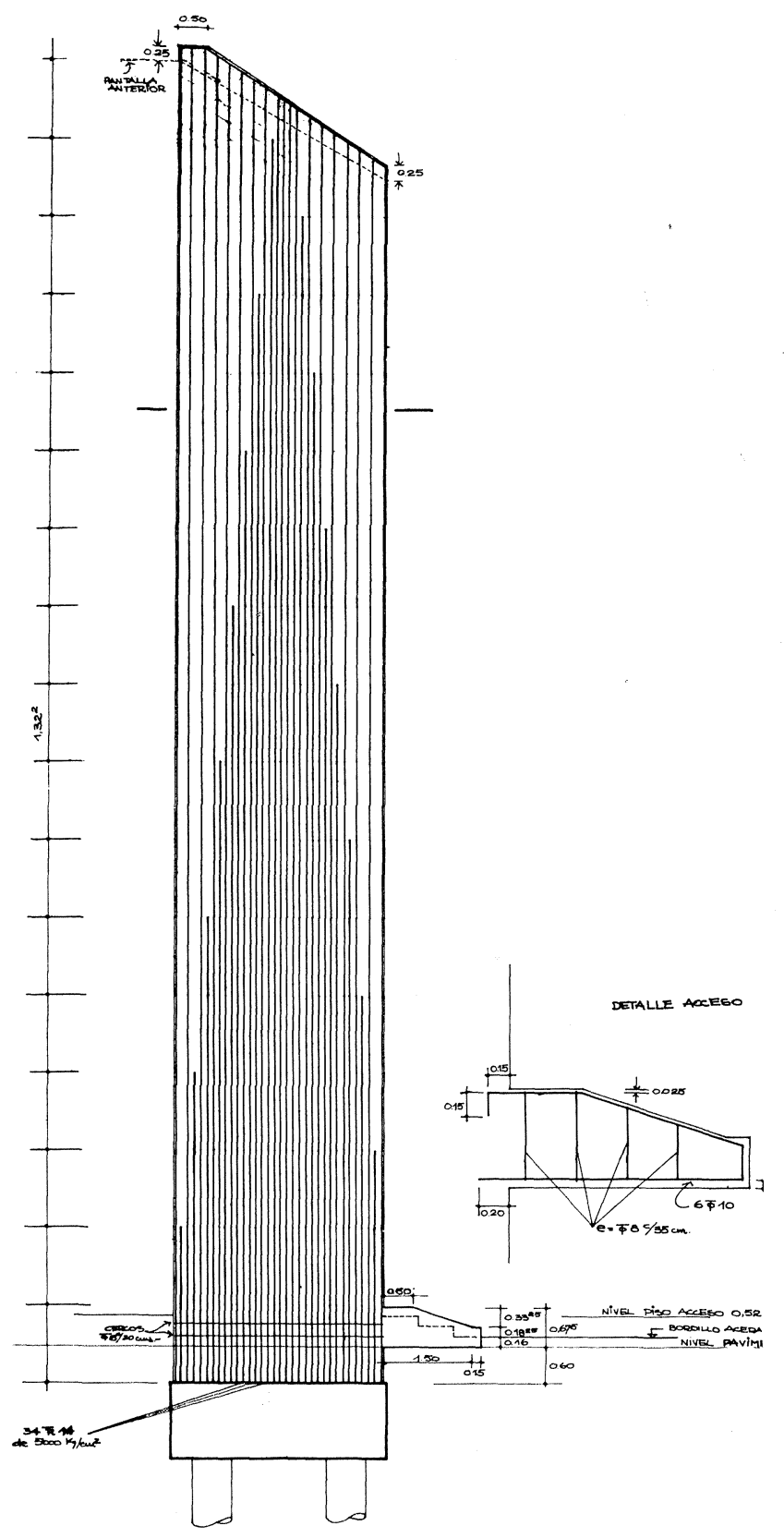

armadura pantalla (escalera)

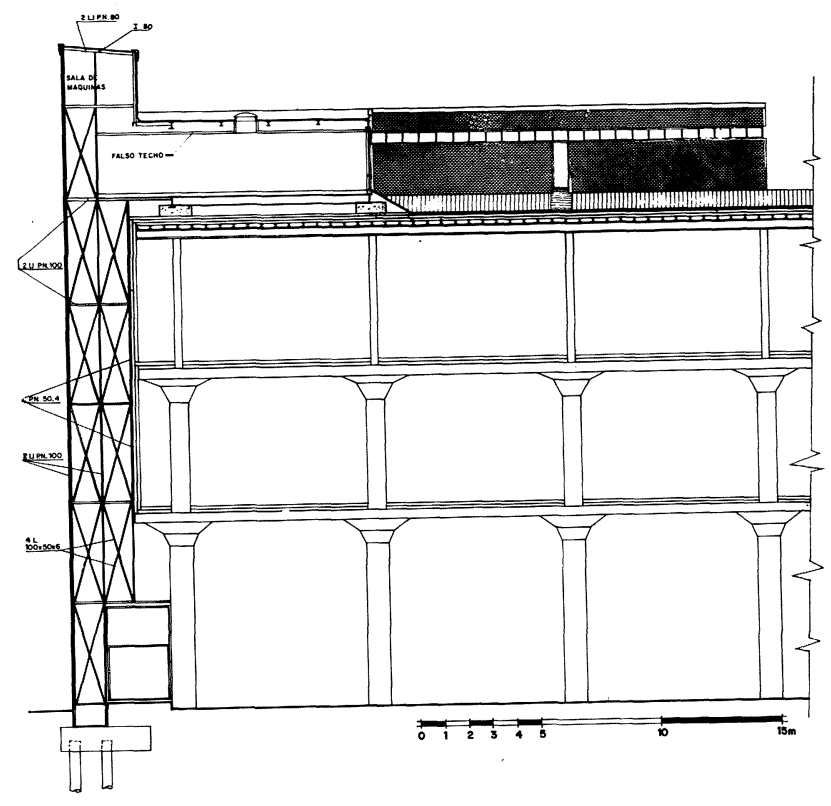

sección

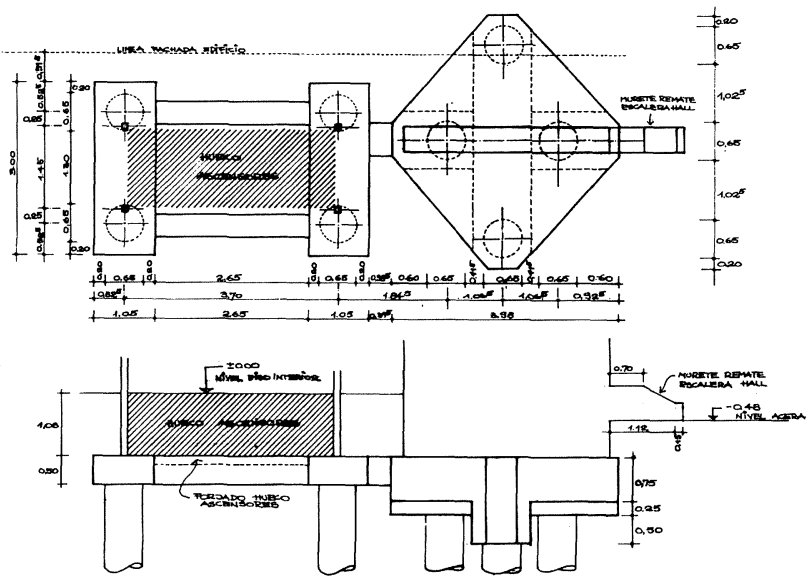

cimentación

debe tener y la altura a salvar, se dejó descubierta. Se realizó a base de una sutil malla metálica galvanizada y con los petos del pasamanos de chapa de aluminio.

El núcleo de la escalera es, junto con las zapatas, la única obra húmeda del edificio, pues el resto de la estructura es metálica galvanizada y los paramentos de aluminio al exterior y de en cartón-yeso-cartón en el interior, se diseñó para funcionar ante el viento como una ménsula, siendo necesario empotrarlo con un encepado de hormigón que a su vez descansa en un sistema de pilotes. Se dejó de hormigón visto realizado con un encofrado rígido de chapa de madera sin juntas, de tal forma, que su resultado, al ser extremadamente liso, diese todo el aspecto industrial que tiene todo el edificio. 
Informes de la Construcción/328

La carpinteria, colocada de un modo continuo sobre el perimetro exterior, ocupa toda la altura libre de la planta por el interior y dibuja en la fachada una especie de junta continua de separación entre el volumen existente y la ampliación agregada.

La chapa de aluminio usada en la nueva obra es del mismo perfil que en la antigua, pero ha sido colocada en color amarillo buscando que, si bien la apariencia metálica del edificio existente continúe en el nuevo, el color contribuya a la diferenciación necesaria.
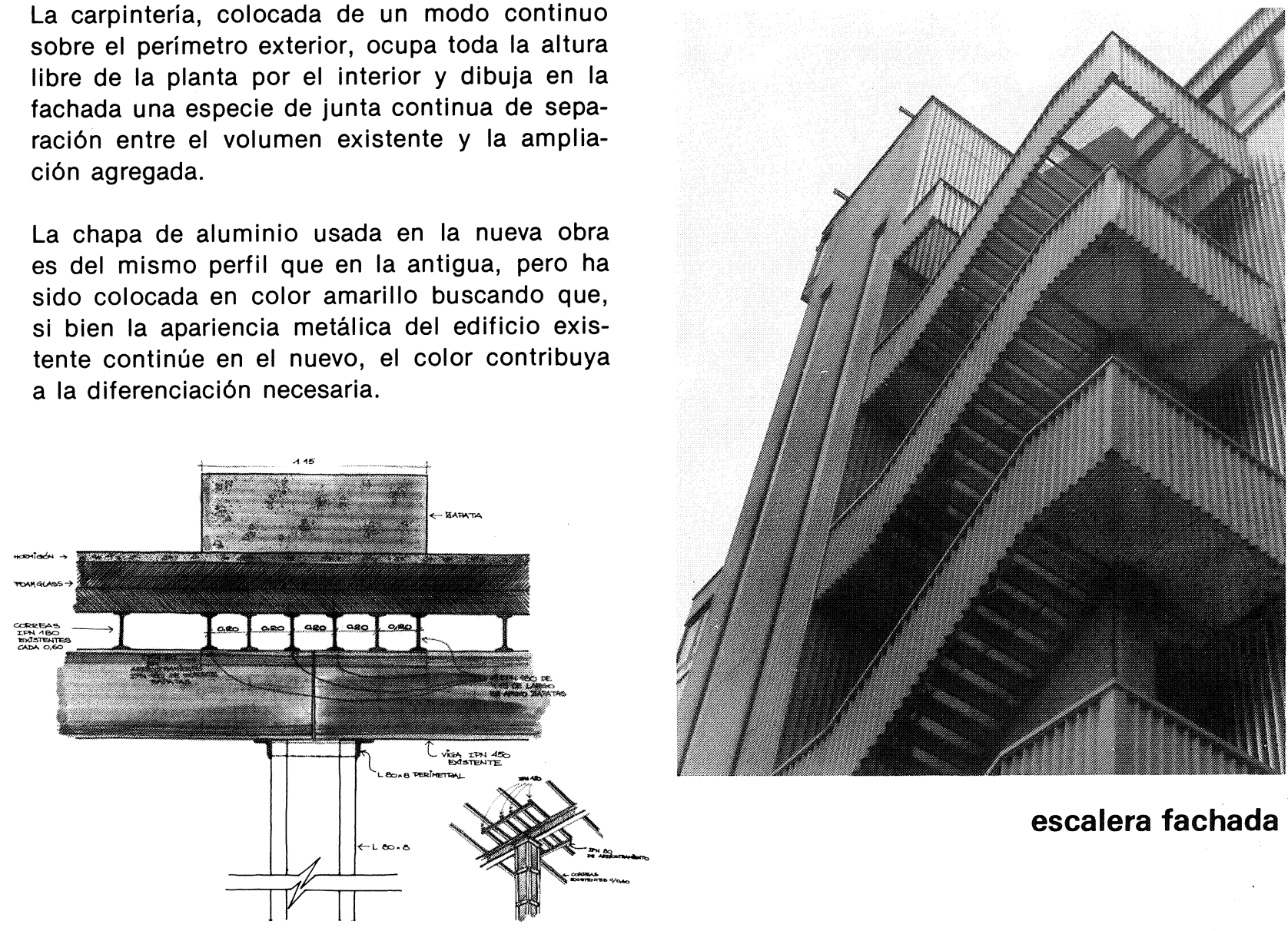

escalera fachada

\section{detalle zapata (oficina)}
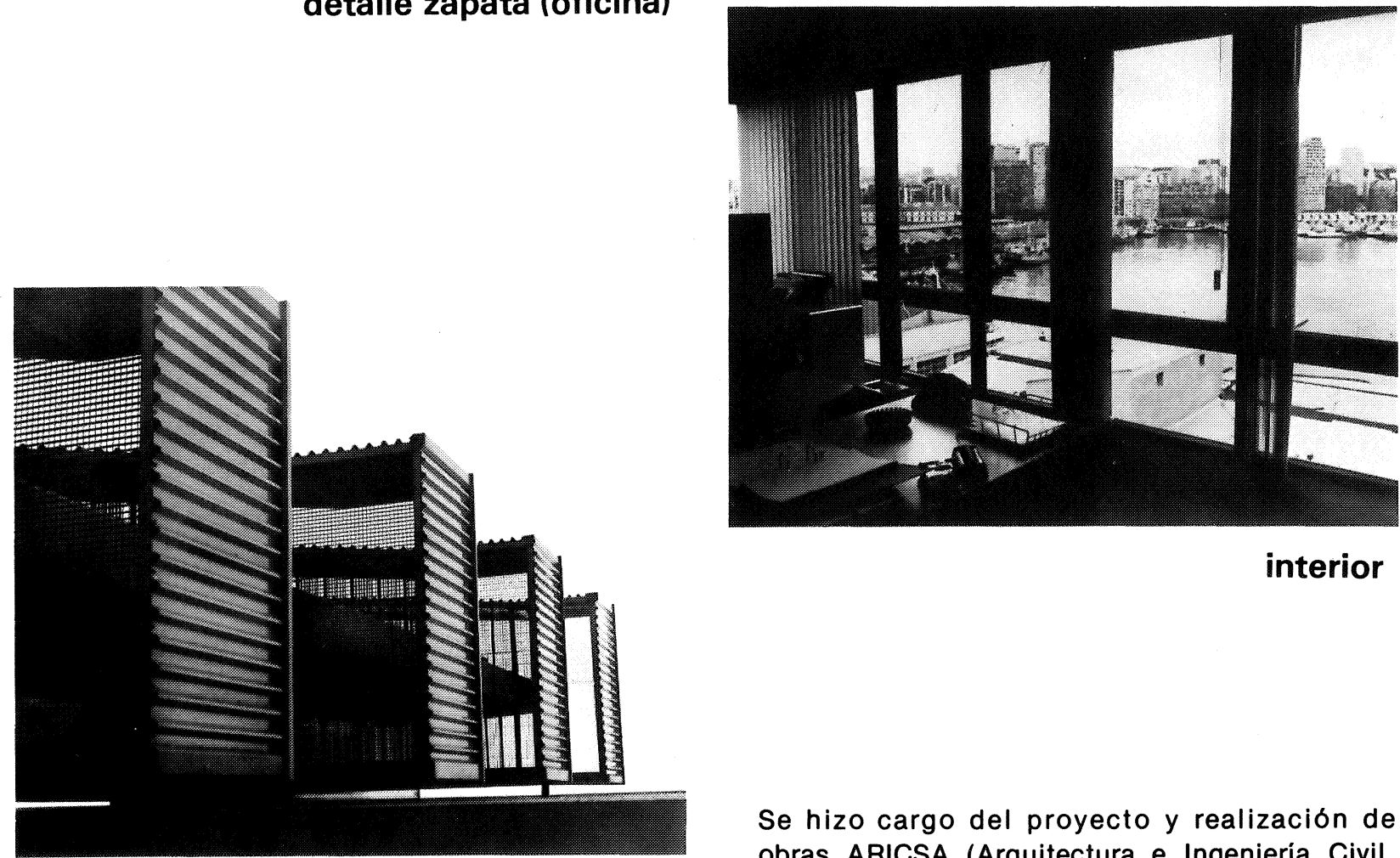

interior

\section{exterior}

